\title{
Signal Based Indirect Wheel Profile Estimation Technique for Solid Axle Railway Wheelset
}

\author{
Khurram Shaikh ${ }^{1 a}$, Imtiaz Hussain Kalwer ${ }^{2}$, Khakoo Mal ${ }^{1 \mathrm{~b}}$, \\ Bhawani Shanker Chowdhry ${ }^{1 \mathrm{c}}$
}

RECEIVED ON 27.09.2018, ACCEPTED ON 03.03.2020

\begin{abstract}
Wheel profile is a very important factor that helps the steering performance of the railway vehicle. However, during the operation, the wheel profile tends to vary inconsistently due to frictional contact at wheel-rail interface. This paper focuses on the problem of railway wheelset profile and its alteration that affects the performance of railway vehicle. Signal-based indirect estimation technique using Fast Fourier Transform (FFT) is proposed to establish a relationship between dynamic response of vehicle and wheel profile. It is observed that changes in wheel profile has direct impact on the frequency of lateral dynamics. The effect of vehicle speed is also analyzed on the yaw and lateral motions of the wheelset. The effectiveness of the proposed technique in determining the relationship between the frequency of the oscillation and conicity level of the solid axle railway wheelset is demonstrated by developing simulation model in MATLAB and Simulink.
\end{abstract}

Keywords: Railway Wheelset Profile, Conicity, Frequency of Oscillation, Rolling Stock

\section{INTRODUCTION}

$\mathrm{T}$ The maintenance of the railway transport wheelset is usually fixed [1-3]. But, the wheel tread may wear down before or after the scheduled maintenance $[2,4]$. If the wear down of the wheel treads occurs before the scheduled maintenance, then it is highly dangerous for the train safety [5]. Because changes in wheel rail profile create problem like excessive vibration and noise and in some cases poses threat of derailment [6]. On the other hand, if the wear down of the wheel treads occurs after the scheduled maintenance, then unnecessary maintenance of railway vehicle causes expense and disturbance in railway schedules due to unavailability of the rolling stock [3]. Predictive maintenance (PdM) techniques use condition monitoring methods to assist in finding out the condition of on-board equipment so as to anticipate when maintenance is required $[7,8]$ and this technique monitors the condition of the railway wheelset profile by continuously inspecting the dynamic changes in the railway wheelset and notifies whether it requires maintenance or not.

The performance of railway system is mainly dependent on the wheel-rail interface [9]. To attain a service with high quality (i.e. punctuality, comfort and safety), well management is required between the interface of vehicle and wheel by considering it as a system [10]. In addition to the wheel-rail interface, there are numerous other factors, such as the track curvature, conicity, friction, the status of the track and the wheelset itself, that have an influence on the wheel-rail interface [11]. However, abnormalities on the profiles of the wheelsets are not detected in general which leads major wear and tear in wheelsets and could cause serious accidents if ignored. Therefore, it is important to monitor not only the rail profiles, but

\footnotetext{
${ }^{1}$ Institute of Information and Communication Technologies, Mehran University of Engineering and Technology, Jamshoro, Sindh, Pakistan. Email: akhuram.shaikh@admin.muet.edu.pk (Corresponding Author),

b malkhakoo@gmail.com, ${ }^{\mathrm{c}}$ hhawani.chowdhry@faculty.muet.edu.pk

${ }^{2}$ Department of Electrical Engineering, DHA Suffa University, Karachi, Pakistan. Email: imtiaz.hussain@ dsu.edu.pk This is an open access article published by Mehran University of Engineering and Technology, Jamshoro under CC BY 4.0 International License.
} 
also the wheel profiles on a regular basis to improve the quality of service. Several researchers have worked to monitor the performance of wheelset. Polach [12] proposed to design a new wheel tread profile in which an interrelationship between the equivalent conicity, contact angle and location of contact area in nominal position, the contact stress and lateral contact spreading was explained. Charles $[13,14]$ provided a practical approach to estimate a nonlinear function within wheel-rail profile dynamic system by using a piecewise cubic functions, the parameters are estimated with a least square approach applied to the dynamic measurements taken from the system. Braghin [15] presented the results of experimental and numerical investigations on regular wear of wheel profiles. Experimental tests were performed on a full-scale roller rig and allowed to measure the evolution of wheel profiles as well as contact forces and several quantities describing the motion of the wheelset. An optimization technique for the railroad wheel profile based on Weibull distribution function is presented by Liu et al. [16] in order to improve the overall adhesion coefficient present at wheel-rail interaction. An effective and simple algorithm works in time domain is elaborated in [17] to identify wheel flat faults using vertical acceleration measurement on the axle-box.

Among several other factors, wheelset profile conicity plays a vital role in the wheelset dynamics. For stable operation of the railway wheelset certain conicity level is required. During the operation the wheelset conicity level is reduced due to wearing of wheel tread. Even a small variation in conicity level can result in serious damage to the wheel tread and track [18-21]. Several vehicle derailments have taken place due to wheel conicity issue, one of them occurred in March 2006, when two wheelsets of tram of the Manchester Metrolink system derailed at Long Millgate, near Victoria Station.

Since railway wheels are stiffly connected to axle, as they rotate with same angular speed, as a result yaw motion is produced which causes the alteration in the alignment of the wheels [20]. An unconstrained solid axle wheelset is not stable at various speeds, crosses the central line and overshoots to the other side [18], showing maintained oscillation while being in lateral plane, called 'wheelset hunting. Klingel [8] showed the reasoning of kinematic oscillation and the association linking the frequency $f$, wheelset conicity $\lambda_{\mathrm{w}}$, wheel radius $\mathrm{r}_{\mathrm{o}}$ and the lateral distance between the contact points of wheels and tracks $2 \mathrm{~L}_{\mathrm{g}}$ by equation (1):

$$
f=\frac{v_{s}}{2 \pi} \sqrt{\frac{\lambda_{w}}{L_{g} r_{o}}}
$$

where $\mathrm{v}_{\mathrm{s}}$ denotes vehicle speed. For well employing a condition-based maintenance in the railway industry, a better condition monitoring tool capable of anticipating and discovering early issues in real time is needed [21].

This research work focuses an extension on the railway wheelset conicity as reported in [19]. In this paper, signal-based estimation technique for railway wheel profile using FFT is proposed, which is simpler and comparatively good efficient than more complex algorithms.

\section{METHOLOGY}

In this research work, an unconstrained solid axle wheelset is considered to demonstrate the potential of the proposed idea. Fig. 1 shows the basic arrangement of wheelset of modern passenger carrying railway vehicle. The equations of motion of railway wheelset are expressed as [22]:

$$
\begin{aligned}
& \mathrm{M}_{\mathrm{v}} \mathrm{x}=\mathrm{F}_{\mathrm{xR}}+\mathrm{F}_{\mathrm{xL}} \\
& \mathrm{m}_{\mathrm{w}} \ddot{\mathrm{y}}_{\mathrm{w}}=-\mathrm{F}_{\mathrm{yR}}-\mathrm{F}_{\mathrm{yL}} \\
& \mathrm{I}_{\mathrm{w}} \ddot{\Psi}_{\mathrm{w}}=\mathrm{F}_{\mathrm{xR}} \mathrm{L}_{\mathrm{g}}-\mathrm{F}_{\mathrm{xL}} \mathrm{L}_{\mathrm{g}}-\mathrm{K}_{\mathrm{w}} \Psi
\end{aligned}
$$

where

$I_{w}=$ Yaw moment of inertia of the wheelset.

$\mathrm{K}_{\mathrm{w}}=$ Yaw stiffness

$\mathrm{M}_{\mathrm{v}}=$ Mass of the vehicle

$\mathrm{m}_{\mathrm{w}}=$ mass of wheelset

$\Psi=$ Yaw angle

$F_{y L}, F_{y R}, F_{x L}$ and $F_{x R}$ are the creep forces of left and right wheels in lateral and longitudinal directions.

A wheelset model is developed from equations (2) to 
(4) and simplified in equation (5) to simulate the behavior of a railway vehicle. In the mathematical model of the wheelset having linearized creep forces, only lateral and yaw dynamics are regarded for preliminary study which can be easily extended by considering other relevant dynamics.

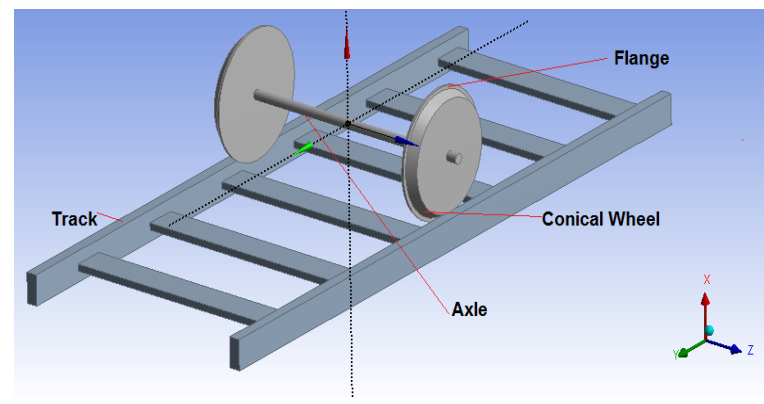

Fig. 1: Railway Wheelset

$\left[\begin{array}{l}\dot{y}_{w} \\ \dot{\Psi}_{w} \\ \ddot{y}_{w} \\ \ddot{\Psi}_{w}\end{array}\right]=$

$\left[\begin{array}{cccc}0 & 0 & 1 & 0 \\ 0 & 0 & 0 & 1 \\ 0 & \frac{2 f_{22}}{m_{w}} & -\frac{2 f_{22}}{m_{w}} & 0 \\ -\frac{2 L_{g} \gamma_{w} f_{11}}{r_{o} I_{w}} & -\frac{k_{w}}{I_{w}} & 0 & -\frac{2 L_{g}^{2} f_{11}}{v_{v} I_{w}}\end{array}\right]\left[\begin{array}{l}y_{w} \\ \Psi_{w} \\ \dot{y}_{w} \\ \dot{\Psi}_{w}\end{array}\right]+$

$\left[\begin{array}{c}0 \\ 0 \\ 0 \\ \frac{2 L_{g} \gamma_{w} f_{11}}{r_{o} I_{w}}\end{array}\right] y_{t}$
In equation (2) $y_{w}$ and $\Psi_{w}$ represent conicity of wheelset and the yaw motion respectively. Whereas $f_{11}$ and $f_{22}$ are longitudinal and lateral creep force coefficients. If all other parameters keep constant during the simulation, then it is clear from the Eq. (5) that the dynamic behavior is only changed when the conicity of the wheelset is varied. The simulation model shown in Fig. 2 is further extended from the previous study [19].

In this model, an accelerometer and gyrometer are installed which is vehicle based modeling approach. Parameter values that are used for the simulation are summarized in Table 1. The impact of conicity and vehicle speed were monitored on the yaw and lateral motions of the wheelset.

\begin{tabular}{|l|l|}
\hline \multicolumn{2}{|c|}{$\begin{array}{c}\text { Table 1: Fixed and variable parameters used in } \\
\text { simulation }\end{array}$} \\
\hline Fixed Parameter & Value \\
\hline Mass of Wheelset $\left(\mathrm{m}_{\mathrm{w}}\right)[\mathrm{Kg}]$ & 1250 \\
\hline Wheels radius $\left(\mathrm{r}_{\mathrm{o}}\right)[$ Meters] & 0.5 \\
\hline $\begin{array}{l}\text { Yaw moment of inertia of the } \\
\text { wheelset }\left(\mathrm{I}_{\mathrm{w}}\right)\left[\mathrm{Kg} / \mathrm{m}^{2}\right]\end{array}$ & 700 \\
\hline Track half gauge $\left(\mathrm{L}_{\mathrm{g}}\right)[\mathrm{Meters}]$ & 0.75 \\
\hline Yaw Stiffness $\left(\mathrm{K}_{\mathrm{w}}\right)[\mathrm{N} / \mathrm{rad}]$ & $5 \times 10^{6}$ \\
\hline Variable Parameters & Values \\
\hline Conicity of Wheel $(\gamma)[$ Radians] & 0.05, \\
& 0.15 \\
\hline Vehicle speed $\left(\mathrm{V}_{\mathrm{s}}\right)[\mathrm{m} / \mathrm{sec}]$ & $10,12,14$ \\
\hline
\end{tabular}

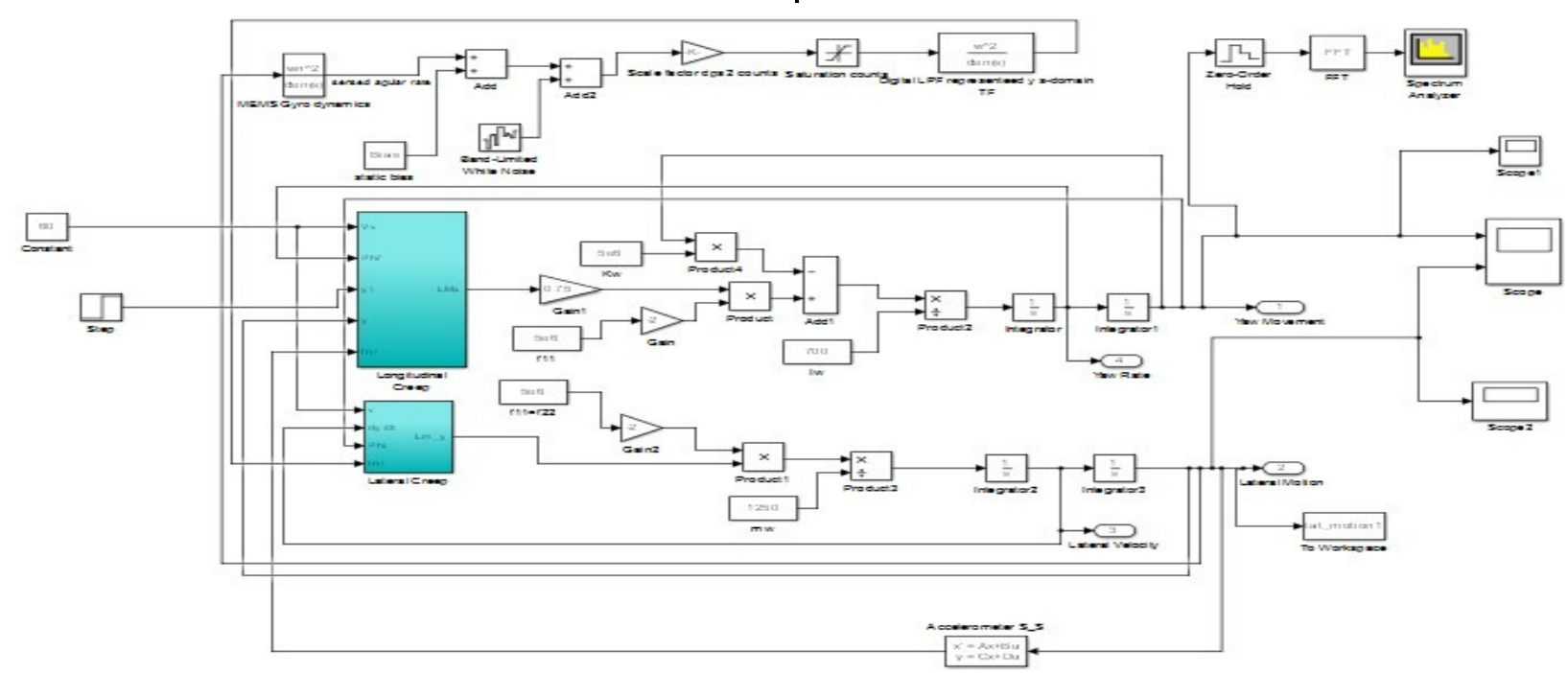

Fig. 2: Simulation model of railway wheelset with accelerometer and gyrometer 


\section{RESULTS AND DISCUSSION}

The developed model was simulated with varying vehicle speed and conicity that ultimately caused the variation in frequency of kinematic oscillations. The varying parameters implemented in the simulation are tabulated in Table 2 . The simulations were developed using yaw stiffness of magnitude $5 \times 106 \mathrm{~N} / \mathrm{rad}(\mathrm{Kw})$. If all other parameters in equation (5) are kept constant, then the frequency of oscillation will only depend upon conicity of the wheelset. Therefore, the simulations are carried out at different conicity levels, the results of simulation are shown in Fig. 3(a) and (b).

\begin{tabular}{|c|c|c|c|}
\hline \multicolumn{4}{|c|}{ Table 2: Simulated Cases between Vehicle speed, } \\
Conicity and Frequency \\
\hline S. No: & Vehicle speed & Conicity & Frequency \\
\hline 1 & 10 & 0.05 & 0.5 \\
\hline 2 & 12 & 0.1 & 0.8 \\
\hline 3 & 14 & 0.15 & 1.1 \\
\hline
\end{tabular}

On low conicity level i.e. 0.05 radian, the frequency of oscillation will be low i.e. $0.5 \mathrm{~Hz}$ which can be observed in Figure 3(a) through equation 1. Similarly, in Fig. 3(b) by increasing the conicity to 0.2 radian, the frequency of oscillation also increased. Hence, if the conicity is lessened, frequency of oscillation will also be decreased. Whereas, decreasing conicity below 0.05 radian means that the wheel tread is worn out and has almost become cylindrical in shape. Cylindrical wheel tread does not have the tendency to align itself back at the center position. On the other hand, by increasing conicity level beyond 0.2 radian, the ibration frequency will be increased which may cause discomfort to passengers, permanent mechanical component failure and huge noise as the train passes along the track.

From the above mentioned results it is evident that certain range of conicity level is suitable for noise free, vibration free and comfortable railway operation. If the conicity level of in-service vehicle is deviated from the allowable range, then the consequences can be severe. Therefore, a new method is proposed here which can indirectly identify the changes in conicity level by analyzing the changes in spectral properties of inertial signals. The block diagram of the proposed scheme is shown in Fig. 4. The signal captured by inertial sensors is first pre-processed from signal conditioning block, which removes noise content present in the signal and processes the data further to signal processing block. Signal processing block then computes the fast Fourier Transform of the inertial signal. The simulation results are obtained at different conicity levels and are presented in Fig. 5 to Fig. 7.

Fig. 5 shows the FFT of kinematic oscillations when conicity level is low, observing the frequency of oscillation nearly $0.5 \mathrm{~Hz}$. In Figure 6 when conicity is doubled i.e. 0.1 radian then the frequency of oscillation reached to $0.8 \mathrm{~Hz}$.

If the conicity level is further increased to 0.15 radian, the frequency of oscillation will also be increased upto
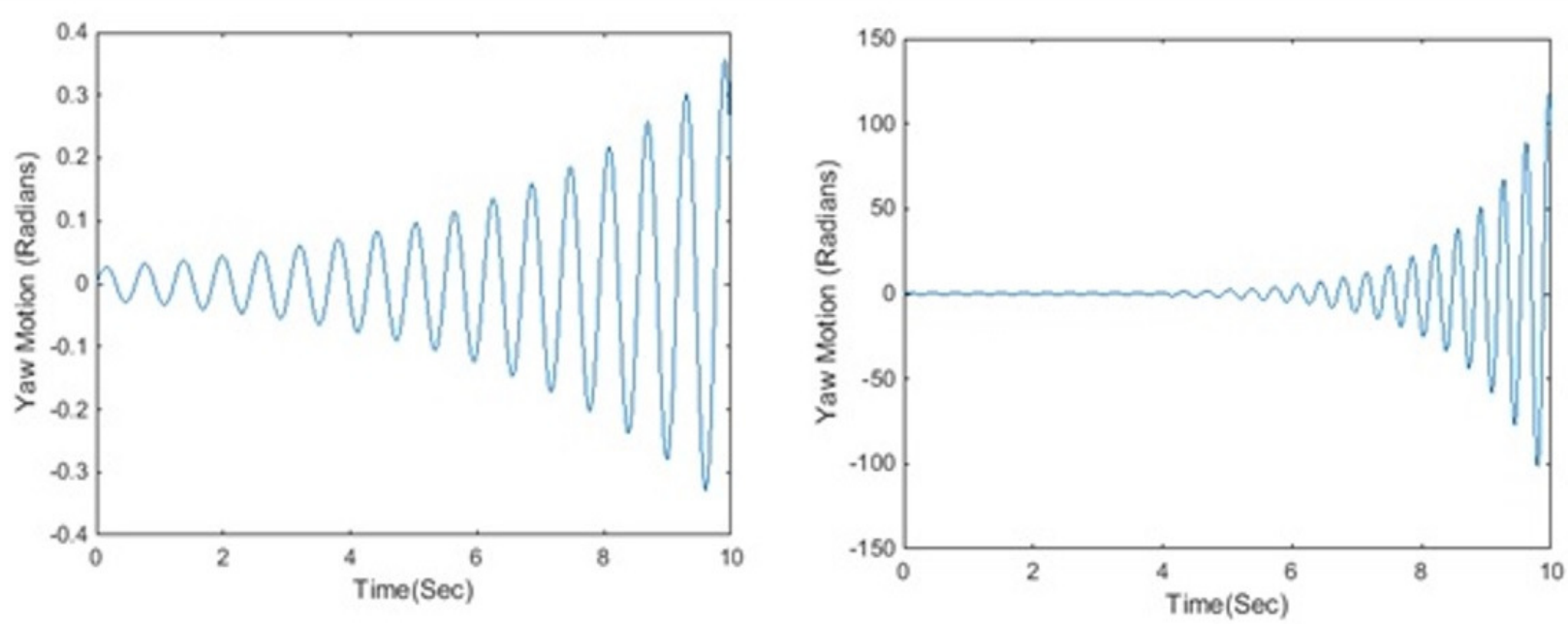

Fig. 3: Step response of Unconstrained Wheelset (a) $\gamma_{w}=0.05$ (b) $\gamma_{w}=0.2$ 


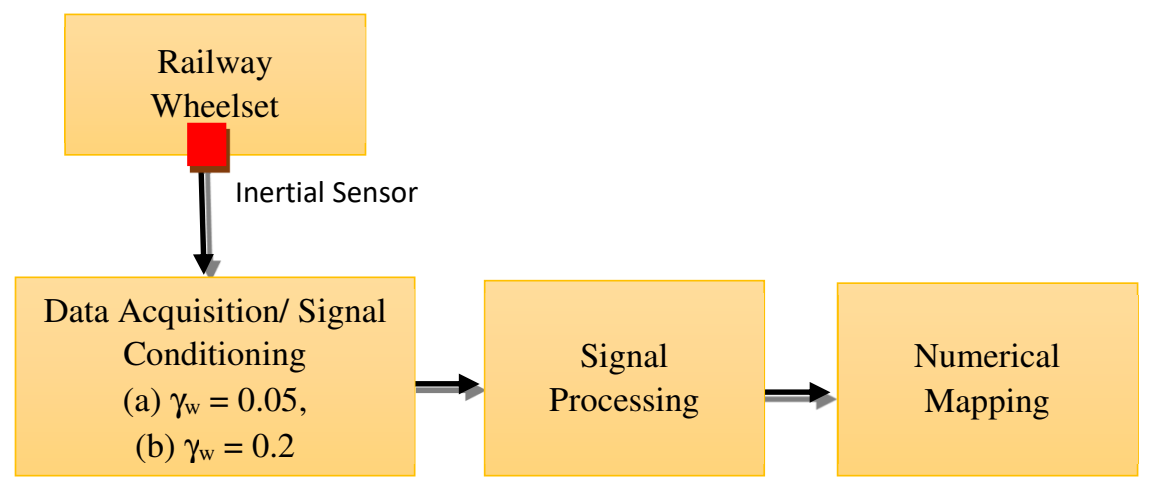

Fig. 4: Block diagram model for identifying changes in Conicity level

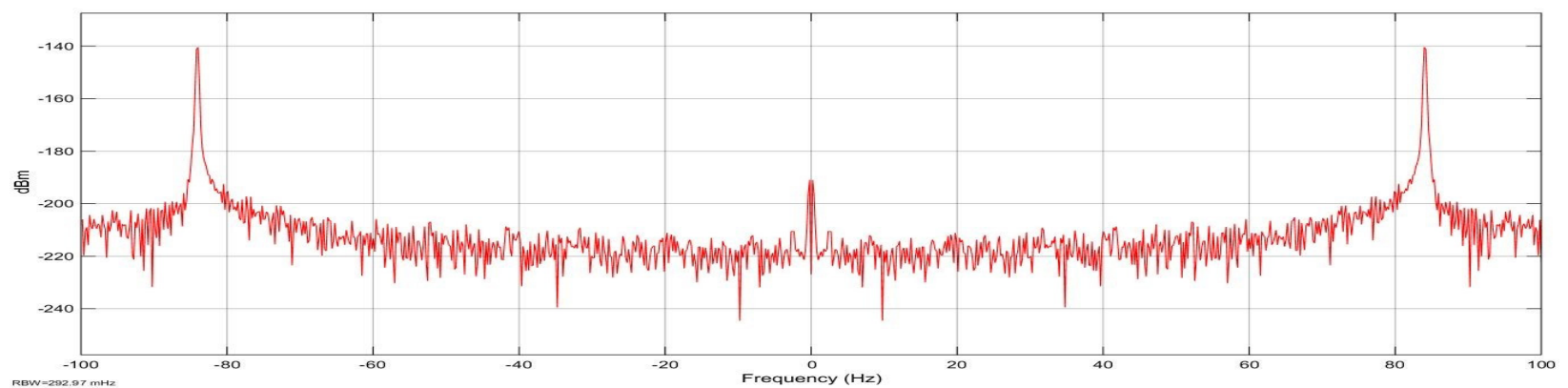

Fig. 5: Frequency Response of the Lateral Acceleration when Vehicle speed $=10 \mathrm{~m} / \mathrm{s}$ and Conicity of Wheel $=0.05$ radians

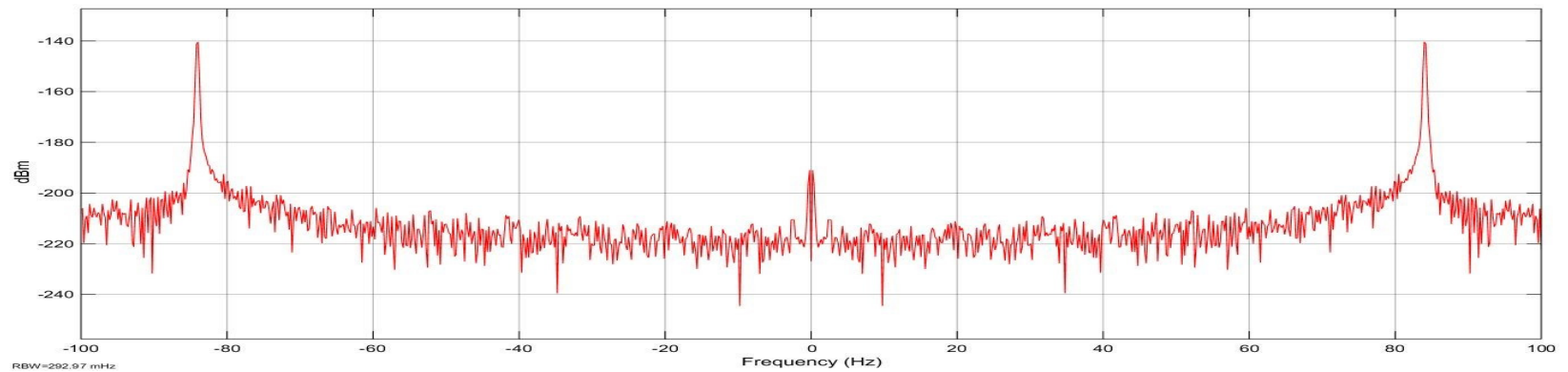

Fig. 6: Frequency Response of the Lateral Acceleration when Vehicle speed $=10 \mathrm{~m} / \mathrm{s}$ and Conicity of Wheel $=0.1$ radians

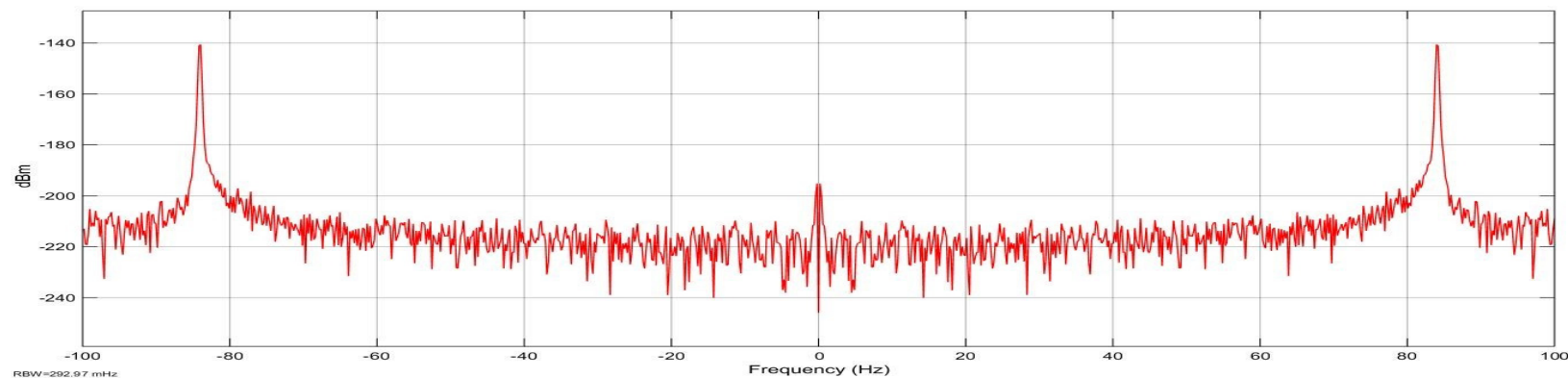

Fig. 7: Frequency Response of the Lateral Acceleration when Vehicle speed $=10 \mathrm{~m} / \mathrm{s}$ and Conicity of Wheel $=0.15$ radians 
$0.9 \mathrm{~Hz}$ as shown in Fig. 7. The simulation results obtained above are summarized in Table 3. In order to derive a numerical relationship between frequency of oscillation and conicity level, the obtained results are plotted with frequency of oscillation on $\mathrm{x}$-axis and corresponding conicity level on $\mathrm{y}$-axis as shown in Fig. 8.

From the said graph a quadratic relationship is obtained between frequency of oscillation and conicity level.

$$
\gamma_{w}=0.14 f^{2}+0.018 f+0.0026
$$

Using equation (6) the conicity level can be easily identified from the spectral properties of the inertial signal.

\begin{tabular}{|c|c|c|}
\hline \multicolumn{3}{|c|}{ Table 3: Frequency vs Conicity Level } \\
\hline S. No & Conicity & Frequency (Hz) \\
\hline 1 & 0.05 & 0.5 \\
\hline 2 & 0.1 & 0.8 \\
\hline 3 & 0.2 & 1.1 \\
\hline 4 & 0.3 & 1.4 \\
\hline 5 & 0.5 & 1.8 \\
\hline 6 & 0.6 & 2.0 \\
\hline
\end{tabular}

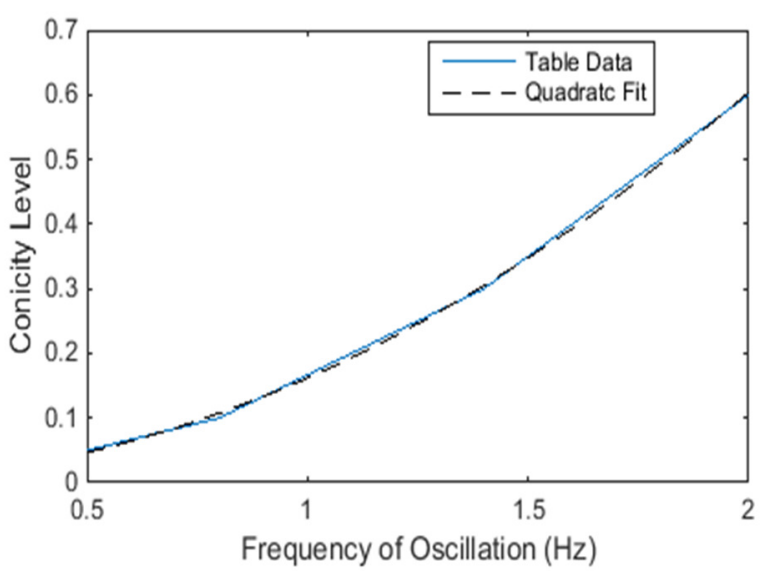

Fig. 8: Conicity Level vs Frequency of Oscillation

\section{CONCLUSION}

In this research, the dynamics for angular speed of railway wheelset modeling are discussed and model is developed with varying vehicle speed, frequency and conicity. It is concluded that decreasing conicity below 0.05 radian, wheelset almost lost its tendency to align itself back at the center position. On the other hand, by increasing conicity level beyond 0.2 radian, the vibration frequency will get increased which may cause discomfort to passengers and mechanical component failure. Therefore, it is necessary in proper operation of railway that the certain conicity level need to be maintained to ensure safe and comfortable operation of railway transport. In this paper, a new method is proposed which indirectly identifies the changes in conicity level by analyzing the changes in spectral properties of inertial signals.

However, the signal processing technique used here is very basic and not suitable for real time signals. As such, another advanced signal processing method such as wavelet transform or Hilbert Transform may be considered as a better option in future.

\section{ACKNOWLEDGEMENT}

The authors would like to acknowledge "Condition Monitoring System Lab at Mehran University of Engineering and Technology, Jamshoro, part of NCRA project of Higher Education Commission Pakistan, for supporting their work and HEC indigenous program for financial support to one of us (Khurram Shaikh).

\section{REFERENCES}

1. Naranjo J. E., González C., García R., de Pedro T., "Cooperative throttle and brake fuzzy control for CC+Stop \& Go maneuvers", IEEE Transactions on Vehicular. Technology, Vol. 56, No. 4 I, pp. 1623-1630, 2007.

2. Abood K. H.A., Khan R., "Hunting phenomenon study of railway conventional truck on tangent tracks due to change in rail wheel geometry", Journal of Engineering, Science and Technology, Vol. 6, No. 2, pp. 146-160, 2011.

3. Schivelbusch W., The Railway Journey: The Industrialization of Time and Space in the 19th Century, University of California Press, 2014.

4. Simon I., "Handbook of Railway Vehicle Dynamics", CRC Press, 2006.

5. Banerjee N., Saha A. K., Karmakar R., Bhattacharyya R., "Bond graph modeling of a railway truck on curved track", Simulation Modeling Practice and Theory, Vol. 17, No. 1, pp. 22-34, 2009. 
6. Gerlici J., Lack T., "Wheelset/rail geometric characteristics assessment with regard to wheelset rolling," Komunikacie, Vol. 7, No. 1, pp. 5-10, 2005.

7. Chowdhry B. S., Shah A., Uqalili M., Meharan J. P. G., "Design of Low-Cost Smart Catś Eye Reflector Device for Damage Identification of a Bridge", Proceedings of the 6th Global Wireless Summit (GWS), 2018, pp. 256-259, 2018.

8. Sipos R., Fradkin D., Moerchen F., Wang Z., "Log-based predictive maintenance," Proceedings of the ACM SIGKDD International Conference on Knowlowdge Discovery and Data Mining, New York, USA, pp. 1867-1876, 2014.

9. Asplund M., Rantatalo M., "Evaluation of wheel profile measurements by means of the contactpoint function for the wheel-rail interface", Proceedings of the Institute of Mechanical Engineers, Part F: Journal of Rail and Rapid Transit, Vol. 232, No. 4, pp. 1225-1239, 2018.

10. Söderholm P., Norrbin P., "Risk-based dependability approach to maintenance performance measurement", Journal of Quality in Maintenance Engineering, Vol. 19, No. 3, pp. 316-329, 2013.

11. Lewis R., Olofsson U., Wheel-Rail Interface Handbook. Woodhead Publishing Limited, 2009,

12. Polach O., "Wheel profile design for target conicity and wide tread wear spreading", Wear, Vol. 271, No. 1-2, pp. 195-202, 2011.

13. Charles G., Goodall R., Dixon R., "A least mean squared approach to wheel-rail profile estimation", IET Seminar Digest, Vol. 2008, No. 12216, 2008.

14. Charles G., Goodall R., Dixon R., "Wheel-rail profile estimation," IET Seminar Digest, Vol. 2006, No. 11575, pp. 32-37, 2006.

15. Braghin F., Bruni S., Resta F., "Wear of railway wheel profiles: A comparison between experimental results and a mathematical model", Vehicle System Dynamics, Vol. 37, pp. 478-489, 2003.

16. Liu B., Mei T. X., Bruni S., "Design and optimisation of wheel-rail profiles for adhesion improvement", Vehicle System Dynamics, Vol. 54, No. 3, pp. 429-444, 2016.

17. Bosso N., Gugliotta A., Zampieri N., "Wheel flat detection algorithm for onboard diagnostic", Journal of International Measurement Confederation, Vol. 123, No. November 2017, pp. 193-202, 2018.

18. Ward C. P., Goodall R. M., Dixon R., "Wheel-rail profile condition monitoring," IET Seminar Digest, Vol. 2010, No. 4, pp. 1184-1189, 2010.
K., "Modeling and Simulation of Predictive Maintenance Scheme for High Speed Railway Vehicles," Indian Journal of Science and Technology, Vol. 9, No. December, pp. 1-6, 2016.

20. Verma N. K., Gupta V. K., Sharma M., Sevakula R. K., "Intelligent condition based monitoring of rotating machines using sparse auto-encoders", Proceedings of the Internationaol Conference on Prognostics and Health Management Society, New Orleans, USA, October 2013.

21. Shahidi P., Maraini D., Hopkins B., Seidel A., "Estimation of bogie performance criteria through on-board condition monitoring", - Proceedings of the Annual Conference on Prognostics and Health Management Society, pp. 648-657, Forthworth, USA, 2014.

22. Hussain I., Mei T. X., Mirzapour M., "Real time estimation of the wheel-rail contact condtions using multi-Kalman filtering and fuzzy logic", Proceedings of the UKACC International Conference on Control, pp. 691-696, Cardiff, UK, 2012.

19. Shaikh K., Kalwar I. H., Chowdhry B. S., Kazi 